\title{
Development and Characterization of Semi-IPN Silver Nanocomposite Hydrogels for Antibacterial Applications
}

\author{
A. Chandra Babu, ${ }^{1}$ M. N. Prabhakar, ${ }^{2}$ A. Suresh Babu, ${ }^{3}$ \\ B. Mallikarjuna, ${ }^{1}$ M. C. S. Subha, ${ }^{1}$ and K. Chowdoji Rao ${ }^{2}$ \\ ${ }^{1}$ Department of Chemistry, Sri Krishnadevaraya University, Anantapur, Andhra Pardesh 515 003, India \\ ${ }^{2}$ Department of Polymer Science and Technology, Sri Krishnadevaraya University, Anantapur, Andhra Pradesh 515 003, India \\ ${ }^{3}$ Department of Physics, Rayalaseema University, Kurnool, Andhra Pardesh 518 002, India
}

Correspondence should be addressed to K. Chowdoji Rao; chowdojirao@gmail.com

Received 3 January 2013; Revised 16 February 2013; Accepted 19 February 2013

Academic Editor: R. J. Linhardt

Copyright (C) 2013 A. Chandra Babu et al. This is an open access article distributed under the Creative Commons Attribution License, which permits unrestricted use, distribution, and reproduction in any medium, provided the original work is properly cited.

Sodium carboxymethyl cellulose/poly(acrylamide-co-2-acrylamido-2-methylpropane sulfonic acid) semi-interpenetrating polymer network (semi-IPN) hydrogels were prepared by using free radical polymerization technique. Silver nanoparticles were formed by reduction of silver nitrate in semi-IPN hydrogels with sodium borohydrate at room temperature. UV-visible spectroscopy, thermogravimetrical analysis, X-ray diffractometry, scanning electron microscopy, and transmission electron microscopy techniques were used to characterize the formation of silver nanoparticles in hydrogels. SEM images indicated clearly the formation of group of silver nanoparticles with size range of 10-20 nm. The sizes of silver nanoparticles were also supported by transmission electron microscopy results. The semi-IPN silver nanocomposite hydrogels reported here might be a potentially smart material in the range of applications of antibacterial activity.

\section{Introduction}

Nanocomposite polymer hydrogels may be defined as crosslinked three-dimensional polymer networks swollen with water or biological fluids in the presence of nanoparticles. The design and development of such materials containing metallic nanoparticles have scientific and technological research interests in recent years due to their unique and versatile properties [1-5]. These properties lead to potential applications in the field of numerous physical, biological, biomedical, and pharmaceutical sectors [6-13] as well as optical, electrical, chemical, and data storage [14-18]. These properties are known for silver in the form of ions, colloidal particles, nanoparticles, metallic silver, and silver compounds, and many works study their use to inhibit the proliferation of microorganisms for medical [19-21], food packaging [22, 23], and water treatment $[24,25]$ applications. Generally silver ions, as heavy metals, lead to the inactivation of proteins reacting with thiol groups $(-\mathrm{SH})$ on the membrane of bacteria causing the microbial cell death [26-28].
The biological activity of silver, especially the antibacterial property, is size dependent [29]. Thus silver nanoparticles should be small enough to pass through the cell membrane. Silver ions kill microorganisms instantly by blocking their respiratory enzyme systems, while having no negative effect on human cells. Although nanocomposites containing metal NPs have elegant features, the homogeneous dispersion of metal NPs is not easy using a simple process because of their high surface free energy, which may cause agglomeration. Therefore, preparation of such nanocomposites with desired properties (i.e., Ag NPs with convenient size) is an important issue. Thus various strategies have been employed to prepare nanocomposites containing silver nanoparticles with controlled size. One such effective approach reported by Wang et al. [30-32] is the in situ reduction of metal ions in the hydrogel networks. In this method the functional groups of the hydrogel network can act as an anchoring agent for the metal ions before in situ reduction.

Usually, carboxylic acid groups can be used as a transient anchoring agent for attaching silver cations to polymer 
hydrogels, and the silver ion is reduced with sodium borohydride to form nanoparticles [33]. This method of preparation depends on the number of functional groups present to stabilize the silver ions, but the nanoparticles are dispersed within the hydrogel matrix. One successful approach that has been employed is the reductive process in homogeneous matrices. In this approach the previously formed crosslinked polymer's swollen with a solution of silver salts and reducing agent, and then reduction takes place within the polymer matrix [34].

This paper focuses on the current design and use of cellulose-based hydrogels ( $\mathrm{NaCMC/poly(AAm-co-AMPS),}$ which usually couple their biodegradability with a smart stimuli-sensitive behavior. Sodium carboxymethyl cellulose $(\mathrm{NaCMC})$ is an ionic ether of the cellulose with too many major commercial applications. It is a highly water soluble anionic polysaccharide that is widely used in pharmaceuticals, cosmetics, and food industry [35-37]. Then 2-acrylamido-2-methyl-propane sulfonic acid is basically a strong acid [38], which can act as a good hydrophilic monomer, and therefore its copolymers have superswelling properties [39]. In this work we report the results obtained for sodium carboxymethyl cellulose/poly(acrylamide-co2-acrylam-ido-2-methylpropane sulphonic acid) ( $\mathrm{NaCMC/}$ poly(AAm-co-AMPS) semi-IPN hydrogels designed as a new antimicrobial biomaterial. Silver containing $\mathrm{NaCMC/}$ poly(AAm-co-AMPS) samples were characterized by their structural characteristics, swelling, UV-Vis, TGA, X-RD, and SEM as well as by their antimicrobial performances.

\section{Experimental}

2.1. Materials. Acrylamido methyl propane sulphonic acid (AMPS) was purchased from Aldrich Chemicals (St. Louis). Sodium carboxymethyl cellulose (NaCMC) was purchased from HiMedia Chemicals, India. Acrylamide (AAm), N,N-methylenebisacrylamide (MBA), ammonium persulfate (APS), and N,N,N,N-tetra methyl ethylenediamine (TEMED) were purchased from S.D. Fine Chemicals, India. Silver nitrate $\left(\mathrm{AgNO}_{3}\right)$, Sodium borohydrate $\left(\mathrm{NaBH}_{4}\right)$ were purchased from Merck (Germany). All chemicals were used without further purification, and double distilled water was used for the preparation of all solutions for this study.

2.2. Preparation of Semi-IPN Silver Nanocomposite Hydrogels. $\mathrm{NaCMC/poly(AAm-co-AMPS)} \mathrm{semi-IPN} \mathrm{hydrogels} \mathrm{were}$ synthesized by employing free radical polymerization using $\mathrm{N}, \mathrm{N}$-methylenebisacrylamide as crosslinker and ammonium persulfate/ $\mathrm{N}, \mathrm{N}, \mathrm{N}^{\prime}, \mathrm{N}^{\prime}$-tetramethylethylenediamine as redoxinitiating pair. First, $0.90 \mathrm{gm}$ of AAm and $0.10 \mathrm{~g}$ of $\mathrm{NaCMC}$ were dissolved in $3 \mathrm{~mL}$ of distilled water in a $250 \mathrm{~mL}$ beaker under constant stirring. To this reaction mixture, $0.99 \mathrm{gm}$ of AMPS was added as a comonomer. Then $0.09 \mathrm{gm}$ of MBA as a hydrophilic crosslinker and $0.49 \mathrm{gm}$ of APS and $0.86 \mathrm{mM}$ of TMEDA as an initiating pair system were added to this solution. After the addition of the reactants, the temperature of the system was raised to $50^{\circ} \mathrm{C}$ for $30 \mathrm{~min}$. After the reaction has been completed, the formed hydrogel was immersed

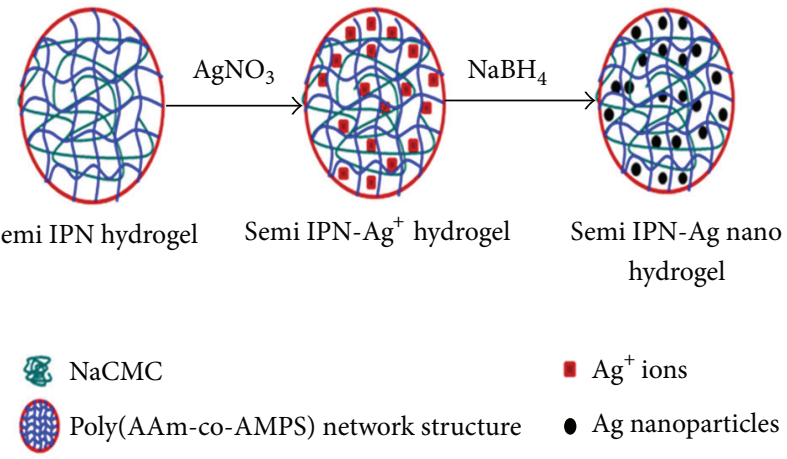

SCHEME 1: Schematic representation of formation of Ag nanoparticles in the polymeric network.

in distilled water at room temperature for $24 \mathrm{~h}$ to remove the unreacted materials present in the hydrogel network. Finally, the hydrogel was dried at room temperature for 2 days. Similarly, other hydrogels were prepared by the above procedure. Different types of hydrogels prepared along with their feed composition are presented in Table 1.

The loading of silver nanoparticles into the hydrogel networks has been performed using the following procedure. Accurately weighed dried copolymeric hydrogels were swelled in double distilled water for 3 days. These swollen copolymeric hydrogels were then transferred into another beaker containing $50 \mathrm{~mL}$ of aqueous $5 \mathrm{mM} \mathrm{AgNO}_{3}$ solution and then allowed to equilibrating the hydrogel for 24 hours to absorb the silver salt. During this process, most of the silver ions were loaded into free-network spaces of hydrogel. These hydrogels with absorbed silver ions were finally transferred into a beaker containing $50 \mathrm{~mL}$ of $10 \mathrm{mM} \mathrm{NaBH}_{4}$ aqueous solution and kept for 2 hours to reduce the silver ions into silver nanoparticles. After reduction of silver ions, the hydrogel was turned into brown colour, which confirms the formation of silver nanoparticles in copolymeric hydrogel matrix as shown in Scheme 1.

2.3. Swelling Studies. Fully dried semiIPN hydrogels, silver nanocomposite hydrogels were accurately weighed and equilibrated in distilled water at $37^{\circ} \mathrm{C}$ for 3 days. The equilibrium swelling capacity or swelling ratio $(Q)$ of the hydrogels was calculated by employing

$$
Q=\frac{W_{e}}{W_{d}}
$$

where $W_{e}$ is the weight of swollen hydrogel and $W_{d}$ is the dry weight of the semiIPN hydrogel.

2.4. Characterization. UV-visible spectra of semiIPN hydrogel silver nanocomposites $\left(10 \mathrm{mg}\right.$ in $1 \mathrm{~mL}$ of distilled $\mathrm{H}_{2} \mathrm{O}$ ) were characterized using (Lab India UV $3000^{+}$) UV-Visible spectrophotometer; X-ray diffraction measurements were also carried out for these nanocomposites using A Siemens D 5000 (Germany) Powder X-ray diffractometer to know the crystallinity of the hydrogel. Thermal properties of semiIPN 
TABLE 1: Various formulation parameters used in the preparation of the hydrogels.

\begin{tabular}{|c|c|c|c|c|c|c|}
\hline Sample code & AAm (gm) & $\mathrm{NaCMC}(\mathrm{gm})$ & AMPS (gm) & MBA (gm) & APS (gm) & TEMED (mM) \\
\hline SIPN-1 & 0.9 & 0.05 & 0.99 & 0.09 & 0.49 & 0.860 \\
\hline SIPN-2 & 0.9 & 0.10 & 0.99 & 0.09 & 0.49 & 0.860 \\
\hline SIPN-3 & 0.9 & 0.15 & 0.99 & 0.09 & 0.49 & 0.860 \\
\hline SIPN-4 & 0.9 & 0.20 & 0.99 & 0.09 & 0.49 & 0.860 \\
\hline SIPN-5 & 0.9 & 0.10 & 0.19 & 0.09 & 0.49 & 0.860 \\
\hline SIPN-6 & 0.9 & 0.10 & 0.29 & 0.09 & 0.49 & 0.860 \\
\hline SIPN-7 & 0.9 & 0.10 & 0.49 & 0.09 & 0.49 & 0.860 \\
\hline SIPN-8 & 0.9 & 0.10 & 1.22 & 0.09 & 0.49 & 0.860 \\
\hline SIPN-9 & 0.9 & 0.10 & 0.99 & 0.02 & 0.49 & 0.860 \\
\hline SIPN-10 & 0.9 & 0.10 & 0.99 & 0.04 & 0.49 & 0.860 \\
\hline SIPN-11 & 0.9 & 0.10 & 0.99 & 0.07 & 0.49 & 0.860 \\
\hline SIPN-12 & 0.9 & 0.10 & 0.99 & 0.12 & 0.49 & 0.860 \\
\hline
\end{tabular}

hydrogels were evaluated by using SDT-Q600 thermal system at heating rage of $10^{\circ} \mathrm{C} / \mathrm{min}$ under $\mathrm{N}_{2}$ atmosphere (flow rate $100 \mathrm{~mL} / \mathrm{min}$ ). Morphological variations of dry hydrogel, silver nanocomposite hydrogel were studied using JSM 6400 Scanning Electron Microscope (SEM) (Japan), operating at an acceleration voltage of $15 \mathrm{~K}$ volts coating with a thin layer of palladium gold alloy. Particle size of silver nanoparticles was performed out by using a Tecnai F 12 Transmission Electron Microscope (TEM) operating at an acceleration voltage of $15 \mathrm{kV}$.

\section{Results and Discussion}

3.1. Swelling Studies. In this study, acryl amide and AMPS were copolymerized in the presence of NaCMC to obtain $\mathrm{NaCMC/poly} \mathrm{(AAm-co-AMPS)} \mathrm{semi-IPN} \mathrm{hydrogels,} \mathrm{where}$ the NaCMC chains are randomly distributed throughout the gel networks. The special interest in choosing $\mathrm{NaCMC}$ as an interpenetrating polymer in hydrogels is due to its viscosity increasing, binding, protecting, reducing, stabilizing, and disintegration properties [40], that is widely used in pharmaceutical applications. The main criterion in selecting AMPS as a comonomer in the preparation of hydrogel is due to the presence of sulphonic acid groups, which are highly water attractive in nature and thereby increase the water absorbing capacity. Hence the hydrogels swell more as the AMPS concentration increases.

Figure 1 shows the swelling studies of various formulations of semi-IPN pure hydrogels and their silver loaded hydrogels. For all these formulations the order of swelling capacity for semi-IPN hydrogels was found to be greater than the silver nanocomposite hydrogels. From Figures 1(a) and (b) it is observed that as the amount of NaCMC and AMPS weight ratio increased, the swelling ratio also increased. This can be attributed due to the presence of polar groups $(-\mathrm{OH}$, $-\mathrm{CONH}_{2},-\mathrm{COO}^{-}, \mathrm{Na}^{+}$, and $\mathrm{SO}_{3} \mathrm{H}$ ) in polymeric chains. The presence of the ionic groups in polymer chains results in increasing of the swelling ratio because the ionic groups are more strongly solvated than the nonionic groups in the aqueous medium.
The effect of crosslinker concentration on the swelling behavior of semi-IPN hydrogels was studied by varying the amount of crosslinker content $0.02-0.12 \mathrm{gm}$. In Figure 1(c) as the crosslinker concentration is increased the swelling ratio decreased this is because the higher the concentration of crosslinker, the higher is the extent of crosslinking in the polymer network and decrease diameter of pores of resultant hydrogels leading to solvent mobility, and then less will be the swelling ratio. Similar observations have been reported in the literature [41-44].

3.2. UV-Visible Spectroscopy. Generally in silver nanoparticles the conduction band and valence band lie very close to each other in which electrons move freely. These free electrons gives rise to a surface plasmon resonance (SPR) absorption band [45-47] (380-500 nm range) occurring due to the collective oscillation of electrons of silver nanoparticles in resonance with the light wave of UV-Vis spectroscopy. The formation of silver nanoparticles in semi-IPN hydrogel networks can be expected in our spectral analysis. Figure 2 illustrates the absorption spectra for hydrogel loaded with $\mathrm{Ag}^{+}$ions in the range of $300 \mathrm{~nm}$ and silver nanocomposites in the range of $380-500 \mathrm{~nm}$. A significant improvement in the absorption peak $\left(\lambda_{\max }=420 \mathrm{~nm}\right)$ was observed due to the surface plasmon resonance (SPR) effect. However, there is no peak observed in pure semi-IPN hydrogel. This spectral analysis confirmed the formation of silver nanoparticles in the semi-IPN hydrogel networks.

3.3. Thermogravimetric Analysis. The semi-IPN silver nanocomposite hydrogels are characterized by thermogravimetrical analysis to determine the percentage of weight loss of pure hydrogel as well as silver nanoparticles in the hydrogel matrix. Figure 3 shows the percentage decomposition of pure hydrogel and silver nanocomposite hydrogel. The pure hydrogel has two decomposition curves at below $500^{\circ} \mathrm{C}$ and $98 \%$ degradation of the hydrogel chains occurs below $800^{\circ} \mathrm{C}$. However, in case of silver nanocomposite hydrogel two degradation curves at below $500^{\circ} \mathrm{C}$, and only $88 \%$ weight 


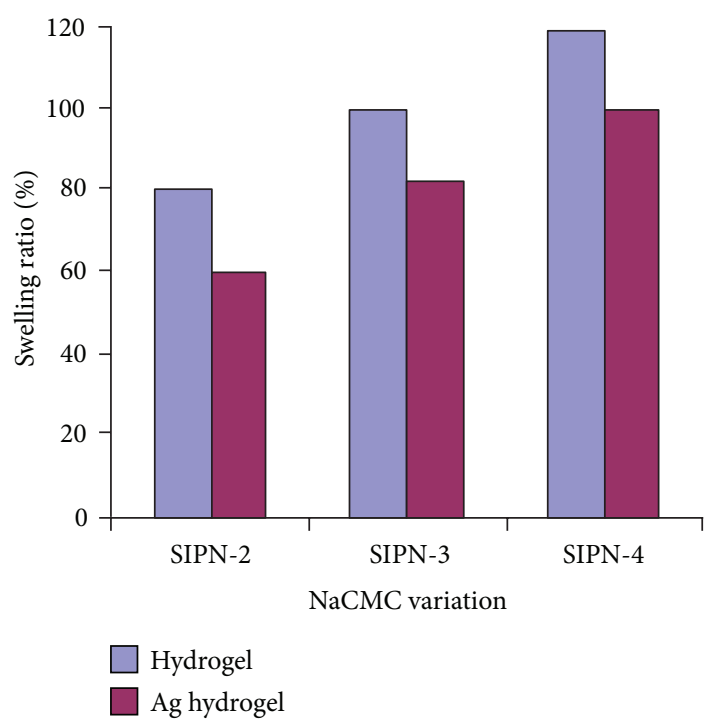

(a)

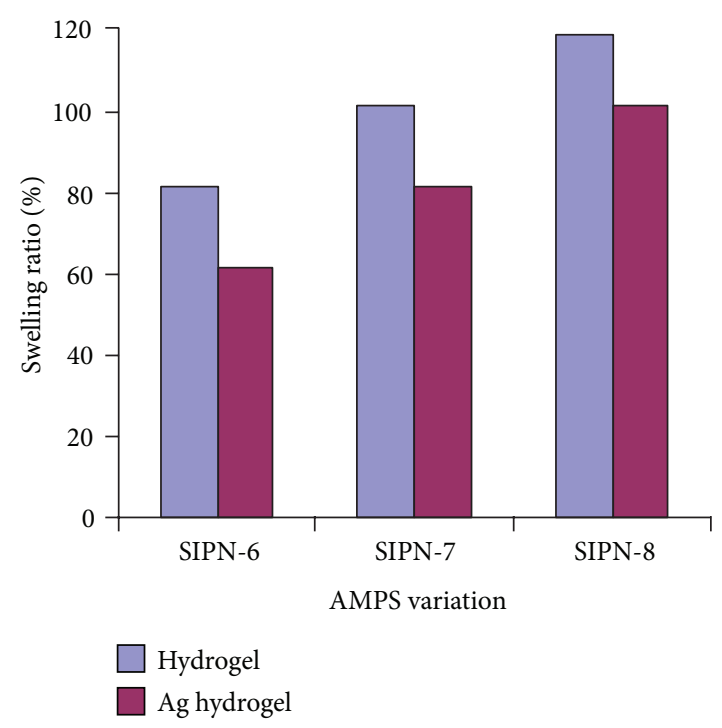

(b)

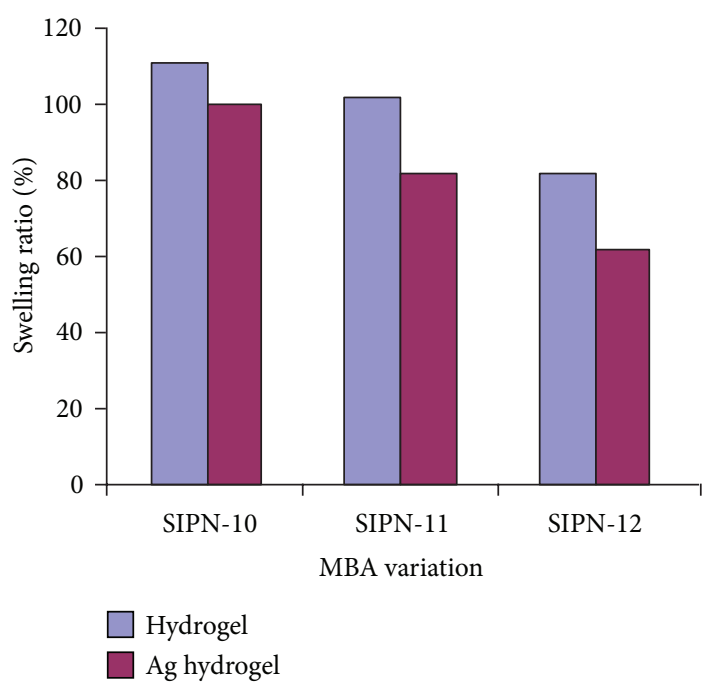

(c)

FIGURE 1: Swelling behavior of semiIPN pure hydrogels and silver nanocomposite hydrogels of various formulations.

loss occurred even at $800^{\circ} \mathrm{C}$. It is expected that the remaining weight of silver particles is left in Ag hydrogel at $800^{\circ} \mathrm{C}$. The difference in decomposition between the hydrogel and silver Nanocomposite hydrogel is found to be $10 \%$, and it confirms the presence of silver nanoparticles in the hydrogel. In the present invention silver nanoparticles play a role in degradation of hydrogel, which restricts the percentage of weight loss.

3.4. X-RD Analysis. The crystallographic nature of the silver nanoparticles in hydrogels was investigated by X-ray diffraction. The X-ray diffraction of pure and silver nanocomposite semi-IPN hydrogels was illustrated in Figure 4. The diffractogram of semi-IPN hydrogel silver nanocomposites is assigned to diffraction at $2 \theta$ value about $38^{\circ}, 44^{\circ}, 65^{\circ}, 77^{\circ}$, and $82^{\circ}$ to the brags reflections of (111), (200), (220), (311), and (222) lattice planes [48], are observed. These peaks are matched with the face centered cubic (FCC) structure of silver (JCPDS card file no. 04-0783). The intense peak represents to highly crystalline silver nanostructures formed in semi-IPN silver nanocomposite hydrogels. In pure hydrogel there is no peak observed; this is due to the absence of silver nanoparticles in pure semi-IPN hydrogel.

3.5. Scanning Electron Microscopy. The scanning electron micrographs of pure hydrogel and silver nanocomposite hydrogels were shown in Figure 5. The pure hydrogel showed branches and rough surface (Figures 5(a) and 5(b)), whereas silver nanocomposite hydrogels showed a shrunken surface (Figures 5(c) and 5(d)) having uniform distribution of silver nanoparticles in size around $10-20 \mathrm{~nm}$. However there is a pin point variation in the case of silver nanoparticles formed in 


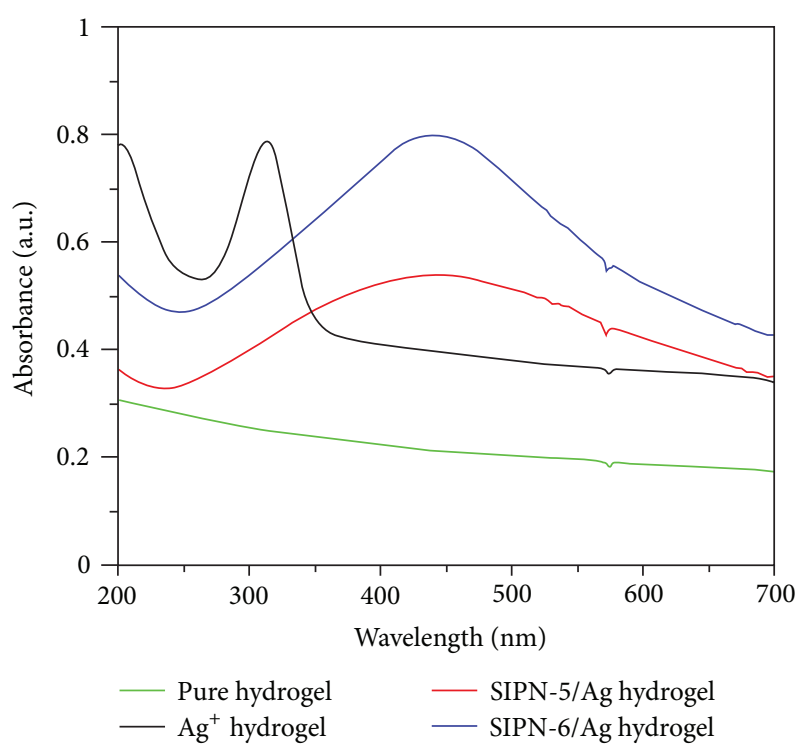

FIGURE 2: UV-visible spectral analysis of pure hydrogel, hydrogel loaded with $\mathrm{AgNO}_{3}$ before reduction, and silver nanocomposite hydrogels.

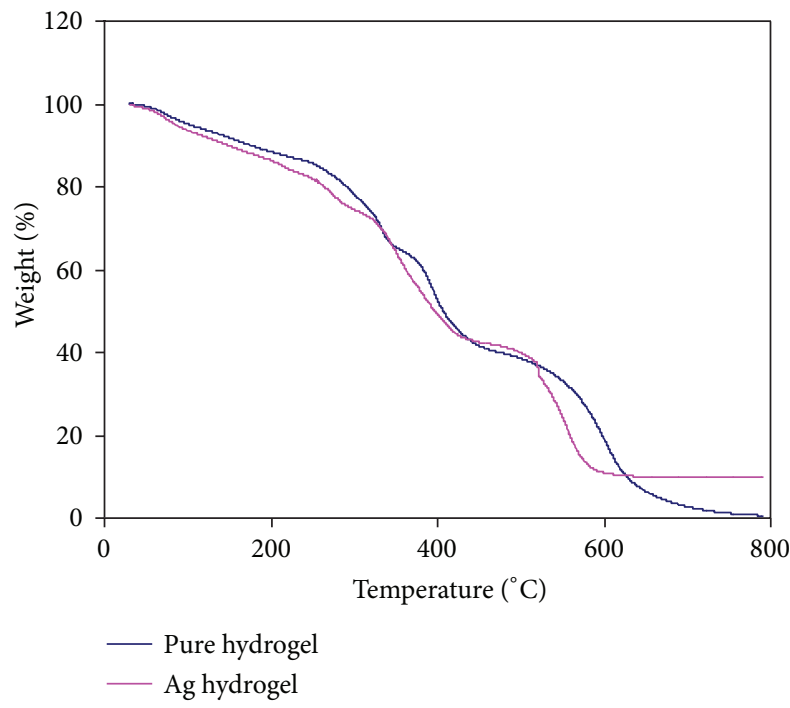

FIGURE 3: Thermogravimetric analysis of pure hydrogel and silver nanocomposite hydrogel.

the gel networks. This clearly indicates the formation of silver nanoparticles along with the polymer chains throughout the gel networks. It reveals that $\mathrm{NaCMC}$ polymeric chains control to lower particle size due to effective reduction and stabilization properties. It is quite common that the control or alignment of silver nanoparticles can be achieved by modifying the hydrogel network architectures.

3.6. Transmission Electron Microscopy. TEM image demonstrates a highly uniform distribution of silver nanoparticles $(20 \mathrm{~nm})$ as shown in Figure 6. It is clear that the silver

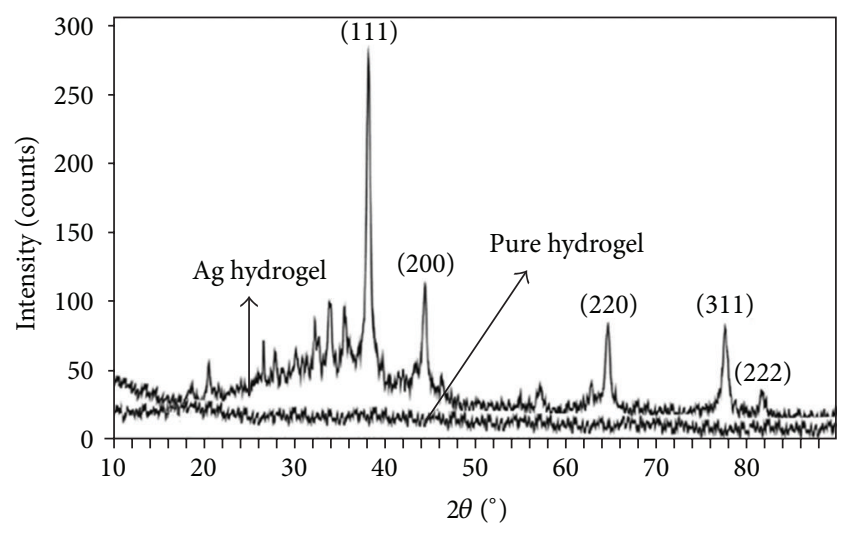

FIgURE 4: X-ray diffraction pattern of pure hydrogel and silver nanocomposite hydrogel.

nanoparticles exhibit obviously no difference in size and morphology because silver $\left(\mathrm{Ag}^{+}\right)$ions were loaded at equilibrium swelling of hydrogel before reduction. The Ag particles were small, regular, when $\mathrm{Ag}^{+}$ions were loaded at the equilibrium swelling ratio of hydrogel. It is confirmed that the silver nanoparticles formed in the crosslinked networks are spherical, highly dispersed, and low nanometer in size.

3.7. Antibacterial Studies. In this study the bacterial effect of silver nanocomposite hydrogels mostly depends on the size of particles and the swelling ratio, which have a direct interaction with the bacteria. Antibacterial studies of pure semi-IPN hydrogel and silver nanocomposite hydrogels were tested by paper disc method using Bacillus subtilis as shown in Figure 7. The results suggest that SIPN-4, SIPN-3, SIPN-2, SIPN-1 have an antibacterial activity against Bacillus subtilis (Gram +ve bacteria), while pure hydrogels were generally inefficient.

The inhibition area follows the order SIPN-4 $>$ SIPN$3>$ SIPN-2 $>$ SIPN-1. This behavior is expected for silver nanoparticles of small sizes $(1-20 \mathrm{~nm})$ and the same order is expected for swelling ratio. So that these silver nanoparticles could come out easily and could interact with lipid layer of cell membrane, thereby attaching to microbial DNA to prevent bacterial replication, which are responsible for inhibition of bacterial growth.

\section{Conclusion}

NaCMC/poly (AAm-co-AMPS) semi-IPN silver nanocomposite hydrogels were successfully prepared via a free radical polymerization along with varying doses of polymer, comonomer, and crosslinking agent thereby reduction of silver ions into silver nanoparticles. The developed silver nanoparticles are well characterized by using different techniques to confirm the formation of silver nanoparticles and antibacterial activity on Bacillus subtilis bactericides. The swelling capacity of the resulting hydrogels was found to be directly related to NaCMC, AMPS, and MBA ratio 


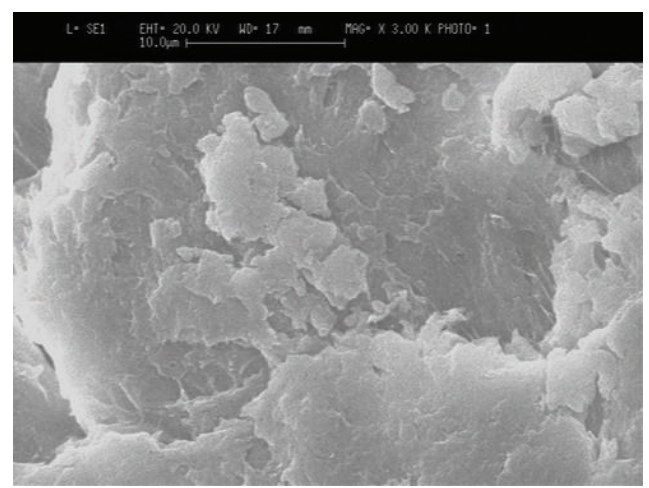

(a)

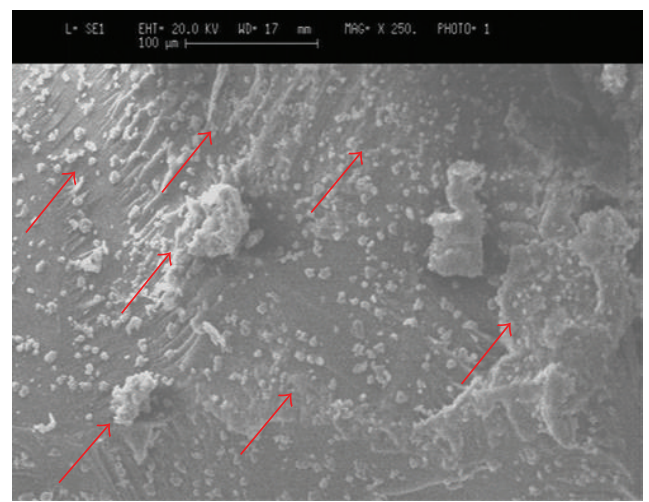

(c)

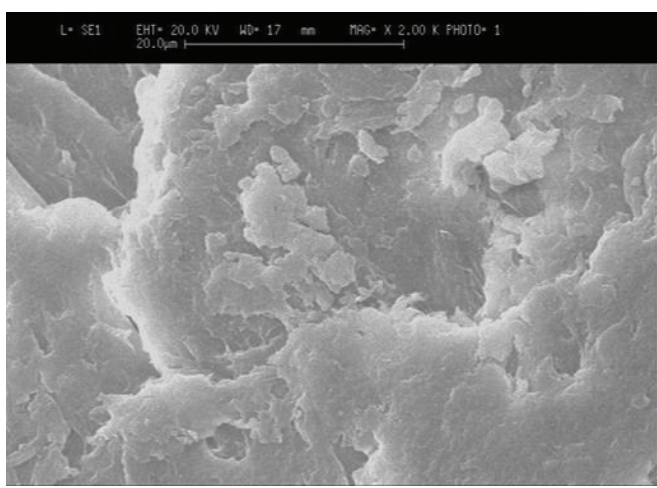

(b)

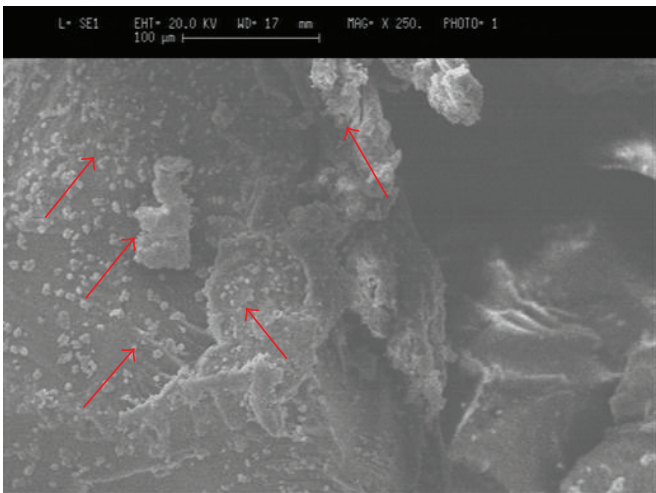

(d)

FIGURE 5: SEM images of pure hydrogels (a) and (b), silver nanocomposite hydrogels (c) and (d).

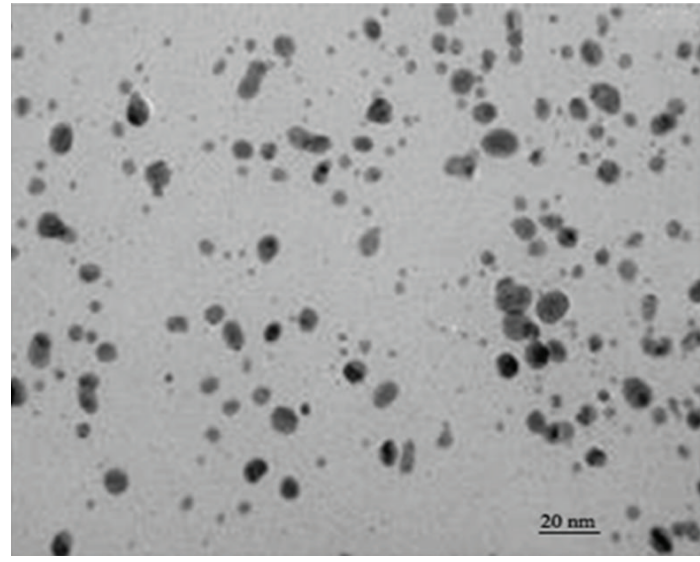

FIGURE 6: TEM image of silver nanocomposite hydrogel.

used in the polymerization process. UV-visible spectra, thermal analysis, and X-RD data revealed the formation of silver nanoparticles through examination of micrographs obtained using SEM and TEM images. The developed silver nanocomposite hydrogels confirmed that small sizes and abundance of silver nanoparticles determine the antibacterial activity.

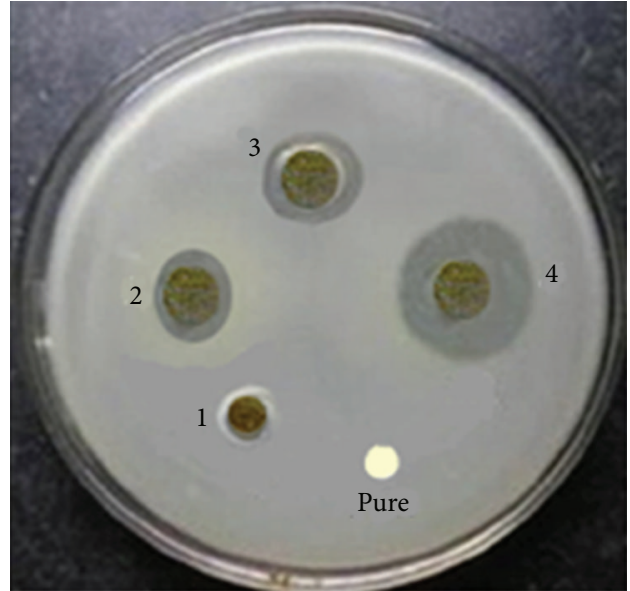

FIGURE 7: Antibacterial activity of silver nanocomposite hydrogels.

\section{Acknowledgments}

The authors (A. C. Babu and K. C. Rao) gratefully acknowledge the support by the Defence Research and Development Organization (DRDO) (Sanction letter no. ERIP/ER/ 1003839 M/1341, dated June 28, 2011) and Ministry of Defense, Government of India, New Delhi, for the financial support. 


\section{References}

[1] M. M. Demir, M. A. Gulgun, Y. Z. Menceloglu et al., "Palladium nanoparticles by electrospinning from poly(acrylonitrile-coacrylic acid) $-\mathrm{PdCl}_{2}$ solutions. Relations between preparation conditions, particle size, and catalytic activity," Macromolecules, vol. 37, no. 5, pp. 1787-1792, 2004.

[2] S. Porel, S. Singh, S. S. Harsha, D. N. Rao, and T. P. Radhakrishnan, "Nanoparticle-embedded polymer: in situ synthesis, freestanding films with highly monodisperse silver nanoparticles and optical limiting," Chemistry of Materials, vol. 17, no. 1, pp. 9-12, 2005.

[3] E. Delamarche, M. Geissler, J. Vichiconti et al., "Electroless deposition of $\mathrm{NiB}$ on 15 inch glass substrates for the fabrication of transistor gates for liquid crystal displays," Langmuir, vol. 19, no. 14, pp. 5923-5935, 2003.

[4] S. G. Boyes, B. Akgun, W. J. Brittain, and M. D. Foster, "Synthesis, characterization, and properties of polyelectrolyte block copolymer brushes prepared by atom transfer radical polymerization and their use in the synthesis of metal nanoparticles," Macromolecules, vol. 36, no. 25, pp. 9539-9548, 2003.

[5] S. Yoda, A. Hasegawa, H. Suda et al., "Preparation of a platinum and palladium/polyimide nanocomposite film as a precursor of metal-doped carbon molecular sieve membrane via supercritical impregnation," Chemistry of Materials, vol. 16, no. 12, pp. 2363-2368, 2004.

[6] W. C. W. Chan and S. Nie, "Quantum dot bioconjugates for ultrasensitive nonisotopic detection," Science, vol. 281, no. 5385, pp. 2016-2018, 1998.

[7] A. P. Alivisatos, "Semiconductor clusters, nanocrystals, and quantum dots," Science, vol. 271, no. 5251, pp. 933-937, 1996.

[8] W. C. W. Chan, D. J. Maxwell, X. Gao, R. E. Bailey, M. Han, and S. Nie, "Luminescent quantum dots for multiplexed biological detection and imaging," Current Opinion in Biotechnology, vol. 13, pp. 40-46, 2002.

[9] X. M. Wu, H. Liu, J. Liu et al., "Immunofluorescent labeling of cancer marker Her2 and other cellular targets with semiconductor quantum dots," Nature Biotechnology, vol. 21, no. 4, pp. 4146, 2003.

[10] I. Brigger, C. Dubernet, and P. Couvreur, "Nanoparticles in cancer therapy and diagnosis," Advanced Drug Delivery Reviews, vol. 54, no. 5, pp. 631-651, 2002.

[11] F. Forestier, P. Gerrier, C. Chaumard, A. M. Quero, P. Couvreur, and C. Labarre, "Effect of nanoparticle-bound ampicillin on the survival of Listeria monocytogenes in mouse peritoneal macrophages," Journal of Antimicrobial Chemotherapy, vol. 30, no. 2, pp. 173-179, 1992.

[12] I. Sondi, O. Siiman, and E. Matijević, "Preparation of aminodextran-CdS nanoparticle complexes and biologically active antibody-aminodextran-CdS nanoparticle conjugates," Langmuir, vol. 16, no. 7, pp. 3107-3118, 2000.

[13] O. Siiman, E. Matijevic, and I. Sondi, "Semi conductor nanoparticles for analysis of blood cell populations and methods of making same," U.S. Patent 6, 235, 540 B1.

[14] A. Biswas, O. C. Aktas, U. Schürmann et al., "Tunable multiple plasmon resonance wavelengths response from multicomponent polymer-metal nanocomposite systems," Applied Physics Letters, vol. 84, no. 14, pp. 2655-2657, 2004.

[15] P. M. Ajayan, L. S. Schadler, and P. V. Braun, Nanocomposite Science and Technology, Wiley-VCH, Weinheim, Germany, 2003.
[16] Y. M. Mohan, K. Lee, T. Premkumar, and K. E. Geckeler, "Hydrogel networks as nanoreactors: a novel approach to silver nanoparticles for antibacterial applications," Polymer, vol. 48, no. 1, pp. 158-164, 2007.

[17] Y. Lu, P. Spyra, Y. Mei, M. Ballauff, and A. Pich, "Composite hydrogels: robust carriers for catalytic nanoparticles," Macromolecular Chemistry and Physics, vol. 208, no. 3, pp. 254-261, 2007.

[18] J. Y. Ouyang, C. W. Chu, C. R. Szmanda, L. P. Ma, and Y. Yang, "Programmable polymer thin film and non-volatile memory device," Nature Materials, vol. 3, no. 12, pp. 918-922, 2004.

[19] K. Yoshida, M. Tanagawa, S. Matsumoto, T. Yamada, and M. Atsuta, "Antibacterial activity of resin composites with silvercontaining materials," European Journal of Oral Sciences, vol. 107, no. 4, pp. 290-296, 1999.

[20] F. Furno, K. S. Morley, B. Wong et al., "Silver nanoparticles and polymeric medical devices: a new approach to prevention of infection?" Journal of Antimicrobial Chemotherapy, vol. 54, no. 6, pp. 1019-1024, 2004.

[21] W. F. Lee and K. T. Tsao, "Preparation and properties of nanocomposite hydrogels containing silver nanoparticles by EX situ polymerization," Journal of Applied Polymer Science, vol. 100, no. 5, pp. 3653-3661, 2006.

[22] S. Quintavalla and L. Vicini, "Antimicrobial food packaging in meat industry," Meat Science, vol. 62, no. 3, pp. 373-380, 2002.

[23] R. Tankhiwale and S. K. Bajpai, "Graft copolymerization onto cellulose-based filter paper and its further development as silver nanoparticles loaded antibacterial food-packaging material," Colloids and Surfaces B, vol. 69, no. 2, pp. 164-168, 2009.

[24] R. Bandyopadhyaya, M. V. Sivaiah, and P. A. Shankar, "Silver-embedded granular activated carbon as an antibacterial medium for water purification," Journal of Chemical Technology and Biotechnology, vol. 83, no. 8, pp. 1177-1180, 2008.

[25] C. Maioli, A. Bestetti, A. Mauri, C. Pozzato, and R. Paroni, "Removal of radioisotopes in solution and bactericidal/ bacteriostatic sterilising power in activated carbon and metal silver filters," Environmental Toxicology and Pharmacology, vol. 27, no. 1, pp. 49-53, 2009.

[26] A. L. Lehninger, D. L. Nelson, and M. M. Cox, Principles of Biochemistry, Worth Publishing, New York, NY, USA, 2nd ed edition, 1993.

[27] S. Y. Liau, D. C. Read, W. J. Pugh, J. R. Furr, and A. D. Russell, "Interaction of silver nitrate with readily identifiable groups: relationship to the antibacterial action of silver ions," Letters in Applied Microbiology, vol. 25, no. 4, pp. 279-283, 1997.

[28] G. McDonnell and A. D. Russell, "Antiseptics and disinfectants: activity, action, and resistance," Clinical Microbiology Reviews, vol. 12, no. 1, pp. 147-179, 2001.

[29] J. R. Morones, J. L. Elechiguerra, A. Camacho et al., "The bactericidal effect of silver nanoparticles," Nanotechnology, vol. 16, no. 10, pp. 2346-2353, 2005.

[30] C. Wang, N. T. Flynn, and R. Langer, "Controlled structure and properties of thermoresponsive nanoparticle-hydrogel composites," Advanced Materials, vol. 16, no. 13, pp. 1074-1079, 2004.

[31] J. Zhang, S. Xu, and E. Kumacheva, "Photogeneration of fluorescent silver nanoclusters in polymer microgels," Advanced Materials, vol. 17, no. 19, pp. 2336-2340, 2005.

[32] A. Biffis, N. Orlandi, and B. Corian, "Microgel-stabilized metal nanoclusters: size control by microgel nanomorphology," Advanced Materials, vol. 15, no. 18, pp. 1551-1555, 2003. 
[33] Y. Xiang and D. Chen, "Preparation of a novel $\mathrm{pH}$-responsive silver nanoparticle/poly(HEMA-PEGMA-MAA) composite hydrogel," European Polymer Journal, vol. 43, no. 10, pp. 4178-4187, 2007.

[34] Y. M. Mohan, K. Lee, T. Premkumar, and K. E. Geckeler, "Hydrogel networks as nanoreactors: a novel approach to silver nanoparticles for antibacterial applications," Polymer, vol. 48, no. 1, pp. 158-164, 2007.

[35] T. Heinze and T. Liebert, "Unconventional methods in cellulose functionalization," Progress in Polymer Science, vol. 26, no. 9, pp. 1689-1762, 2001.

[36] J. H. Guo, G. W. Skinner, W. W. Harcum, and P. E. Barnum, "Pharmaceutical applications of naturally occurring watersoluble polymers," Pharmaceutical Science and Technology Today, vol. 1, no. 6, pp. 254-261, 1998.

[37] K. Pal, A. K. Banthia, and D. K. Majumdar, "Preparation of novel $\mathrm{pH}$-sensitive hydrogels of carboxymethyl cellulose acrylates: a comparative study," Materials and Manufacturing Processes, vol. 21, pp. 877-882, 2006.

[38] C. Saykan, R. Coskun, and S. Kirbag, "Poly(crotonic acid-co-2acrylamido-2-methyl-1-propanesulfonic acid)-metal complexes with copper(II), cobalt(II), and nickel(II): synthesis, characterization and antimicrobial activity," European Polymer Journal, vol. 43, pp. 4028-4036, 2007.

[39] M. V. Dinu, M. M. Ozmen, E. S. Dragan, and O. Okay, "Freezing as a path to build macroporous structures: superfast responsive polyacrylamide hydrogels," Polymer, vol. 48, no. 1, pp. 195-204, 2007.

[40] S. Conti, L. Maggi, L. Segale et al., "Matrices containing NaCMC and HPMC. 1. Dissolution performance characterization," International Journal of Pharmaceutics, vol. 333, no. 1-2, pp. 136-142, 2007.

[41] K. Varaprasad, K. Vimala, S. Ravindra, N. N. Reddy, and K. Mohana Raju, "Development of sodium carboxymethyl cellulose-based poly(acrylamide-co-2acrylamido-2-methyl-1propane sulfonic acid) hydrogels for in vitro drug release studies of ranitidine hydrochloride an anti-ulcer drug," PolymerPlastics Technology and Engineering, vol. 50, no. 1199, 1207 pages, 2011.

[42] A. Pourjavadi, H. Ghasemzadeh, and F. Mojahedi, "Swelling properties of CMC-g-Poly (AAm-co-AMPS) superabsorbent hydrogel," Journal of Applied Polymer Science, vol. 113, no. 6, pp. 3442-3449, 2009.

[43] J. Wu, J. Lin, M. Zhou, and C. Wei, "Synthesis and properties of starch-graft-polyacrylamide/clay superabsorbent composite," Macromolecular Rapid Communications, vol. 21, no. 15, pp. 1032-1034, 2000.

[44] A. S. Hoffmann, "Intelligent polymers (in Medicine and Biotechnology)," in Polymeric Materials Encyclopedia, J. C. Salamone, Ed., vol. 5, p. 3282, CRC Press, Boca Raton, Fla, USA, 1996.

[45] A. Taleb, C. Petit, and M. P. Pileni, "Optical properties of selfassembled 2D and 3D superlattices of silver nanoparticles," Journal of Physical Chemistry B, vol. 102, no. 12, pp. 2214-2220, 1998.

[46] M. A. Noginov, G. Zhu, M. Bahoura et al., "The effect of gain and absorption on surface plasmons in metal nanoparticles," Applied Physics B, vol. 86, no. 3, pp. 455-460, 2007.

[47] U. Kreibig and M. Vollmer, Optical Properties of Metal Clusters, vol. 25, Springer, Berlin, Germany, 1995.

[48] S. L. Amruth, J. S. Sathish, B. P. Ramachandra, and B. P. J, "Synthesis, characterization and dyeing assessment of some novel disperse azodyes based on 1-(4-amino 2-methyl phenyl)2-(n- phenyl amino) ethanone onnylon and polyester fabrics," Journal of Chemical and Pharmaceutical Researc, vol. 2, pp. 478482, 2010. 

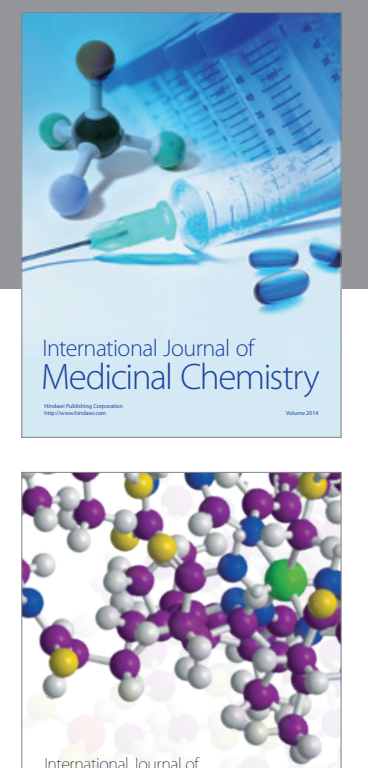

\section{Carbohydrate} Chemistry

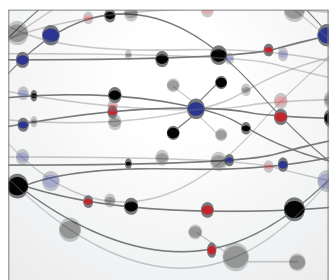

The Scientific World Journal
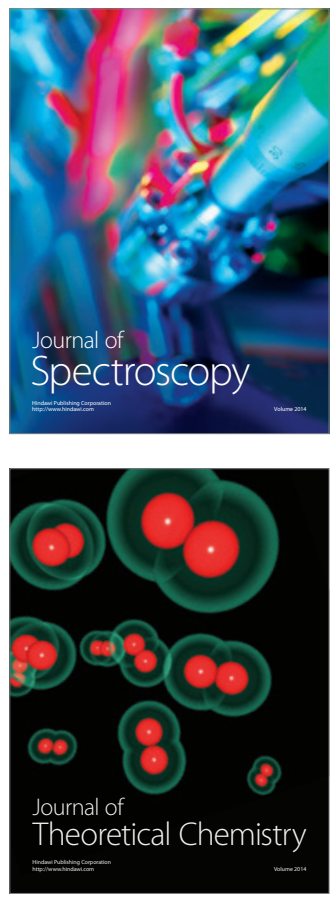
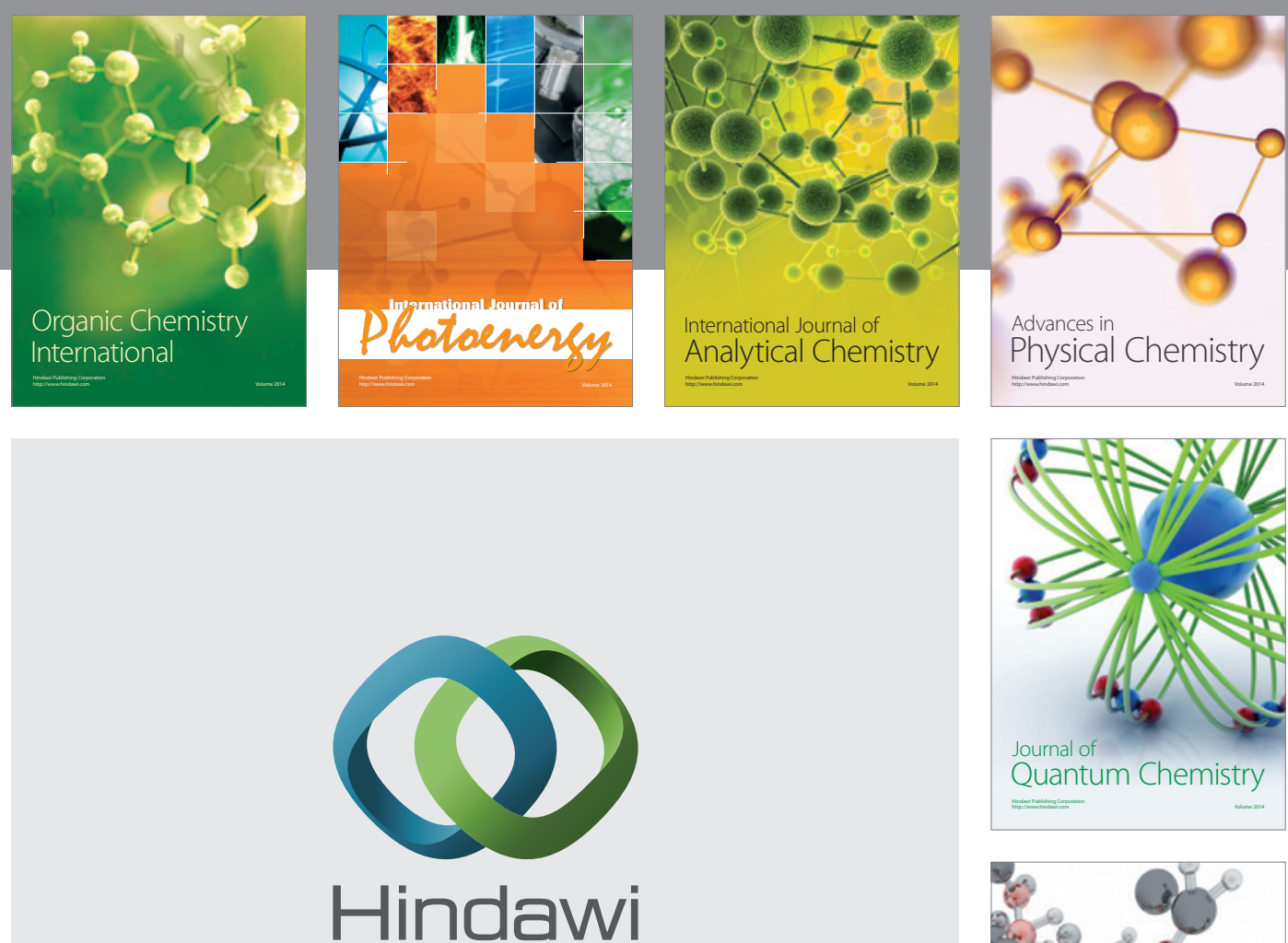

Submit your manuscripts at

http://www.hindawi.com

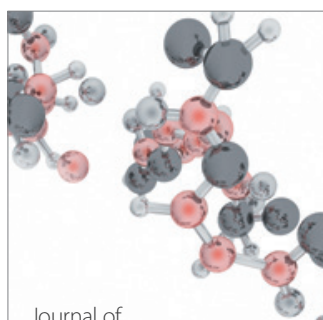

Analytical Methods

in Chemistry

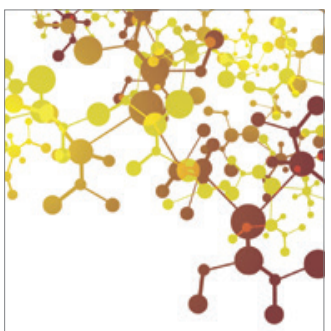

Journal of

Applied Chemistry

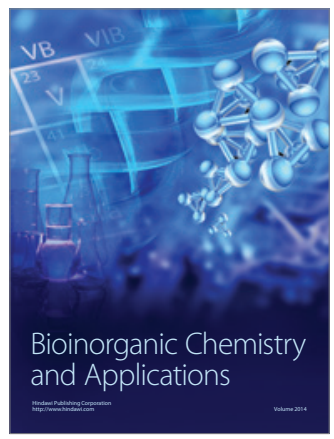

Inorganic Chemistry
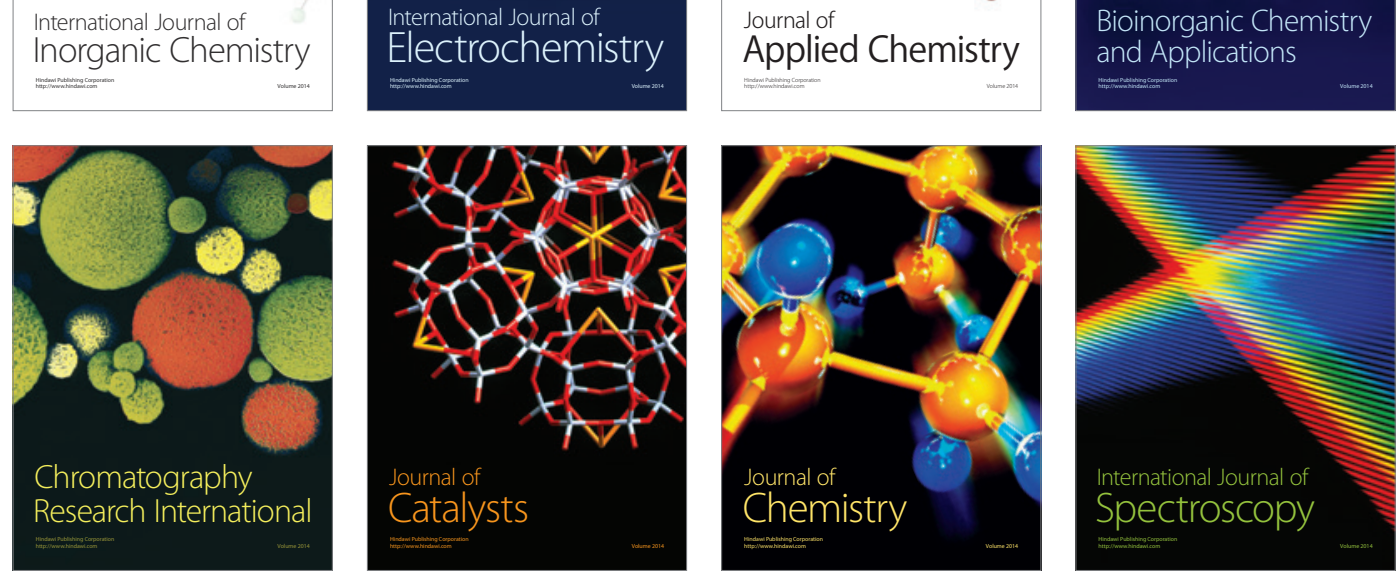